\title{
Correction to: Stress and its correlates among medical students in six medical colleges: an attempt to understand the current situation
}

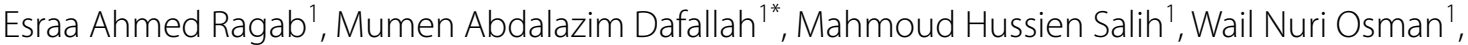 \\ Mugtaba Osman², Elhadi Miskeen ${ }^{3}$, Mohamed H. Taha ${ }^{4}$, Azza Ramadan5, Musaab Ahmed ${ }^{6,7}$, \\ Mohamed Elhassan Abdalla ${ }^{8}$ and Mohamed H. Ahmed ${ }^{9}$
}

\section{Correction to: Curr Psychiatry. 28, 75 (2021) \\ https://doi.org/10.1186/s43045-021-00158-w \\ Following the publication of the original article [1], we were notified of the below corrections:}

- The author affiliations had not been corrected according to the proofs. They have now been updated.

- The first sentence of the Background section was changed from "The medical education curriculum is considered a difficult syllabus is given the breadth and the depth of the material that needs to be learned and the continuous various forms of assessments" TO "The study of medicine is perceived as being stressful and this was attributed to the breadth and the depth of the material that needs to be learned and the continuous various forms of assessments".

- The phrase "It is important to note that besides the pressure the medical students encounter due to academics, they also face non-academic-related sources of stress such as social, emotional, physical, and family problems that may affect their learning abilities and academic performance adversely" was deleted from Page 2.
- The last phrase in "Sources of stressors" was moved at the end of the "Data analysis" section.

- The phrase "It is important to note that besides the pressure the medical students encounter due to academics, they also face non-academic-related sources of stress such as social, emotional, physical, and family problems that may affect their learning abilities and academic performance adversely" was removed from the "Discussion" section.

The original article has been corrected.

\begin{abstract}
Author details
${ }^{1}$ Faculty of Medicine, University of Gezira, Wad Madani, Sudan. ${ }^{2}$ Armed Forces Centre for Psychiatric Care, Taif, Saudi Arabia. ${ }^{3}$ Obstetrics and gynaecology Department, College of Medicine, University of Bisha, Bisha, Saudi Arabia. ${ }^{4} \mathrm{Col}-$ lege of Medicine and Medical Education Centre, University of Sharjah, Sharjah, United Arab Emirates. ${ }^{5}$ College of Pharmacy, Al-Ain University, Abu Dhabi, United Arab Emirates. ${ }^{6}$ College of Medicine, Ajman University, Ajman, United Arab Emirates. ${ }^{7}$ Center of Medical and Bio-allied Health Sciences Research, Ajman University, Ajman, United Arab Emirates. ${ }^{8}$ School of Medicine, Faculty of Education and Health Sciences, University of Limerick, Limerick, Ireland. ${ }^{9}$ Department of Medicine and HIV Metabolic Clinic, Milton Keynes University Hospital NHS Foundation Trust, Eaglestone, Milton Keynes, Buckinghamshire, UK.
\end{abstract}

Published online: 29 December 2021

\section{Reference}

1. Ragab EA et al (2021) Stress and its correlates among medical students in six medical colleges: an attempt to understand the current situation. Curr Psychiatry 28:75. https://doi.org/10.1186/s43045-021-00158-w

*Correspondence: mumenabdalazim36@gmail.com

${ }^{1}$ Faculty of Medicine, University of Gezira, Wad Madani, Sudan

Full list of author information is available at the end of the article original author(s) and the source, provide a link to the Creative Commons licence, and indicate if changes were made. The images or other third party material in this article are included in the article's Creative Commons licence, unless indicated otherwise in a credit line to the material. If material is not included in the article's Creative Commons licence and your intended use is not permitted by statutory regulation or exceeds the permitted use, you will need to obtain permission directly from the copyright holder. To view a copy of this licence, visit http://creativecommons.org/licenses/by/4.0/. 